University of Nebraska - Lincoln

DigitalCommons@University of Nebraska - Lincoln

2012

\title{
Anthropological Data Regarding the Adaptiveness of Hebephilia
}

Raymond B. Hames

University of Nebraska-Lincoln, rhames2@unl.edu

Ray Blanchard

University of Toronto, Faculty of Medicine, ray.blanchard.phd@gmail.com

Follow this and additional works at: https://digitalcommons.unl.edu/anthropologyfacpub

Part of the Anthropology Commons, and the Behavior and Behavior Mechanisms Commons

Hames, Raymond B. and Blanchard, Ray, "Anthropological Data Regarding the Adaptiveness of Hebephilia" (2012). Anthropology Faculty Publications. 51.

https://digitalcommons.unl.edu/anthropologyfacpub/51

This Article is brought to you for free and open access by the Anthropology, Department of at DigitalCommons@University of Nebraska - Lincoln. It has been accepted for inclusion in Anthropology Faculty Publications by an authorized administrator of DigitalCommons@University of Nebraska - Lincoln. 
Published in Archives of Sexual Behavior: The Official Publication of the International Academy of Sex Research 41:4 (2012), pp. 745-747; doi: 10.1007/s10508-012-9972-0

Copyright (C) 2012 Springer Science+Business Media, LLC.

Published online May 30, 2012.

LETTER TO THE EDitor

\title{
Anthropological Data Regarding the Adaptiveness of Hebephilia
}

\author{
Raymond Hames \\ Department of Anthropology, University of Nebraska-Lincoln, Lincoln, NE 68588-0368, USA; email rhames2@unl.edu \\ Ray Blanchard \\ Department of Psychiatry, University of Toronto, Toronto, ON, Canada
}

It is well established that the great majority of human males are most attracted sexually to persons in a particular age range (Blanchard et al., 2012). According to the category of persons who are most attractive sexually to them, five such preferences are commonly distinguished in adult men: pedophilia (prepubertal children in Tanner Stage 1, generally age 10 or younger), hebephilia (early pubertal children in Tanner Stages 2 and 3, generally ages 11 through 14), ephebophilia (late pubertal adolescents in Tanner Stage 4, generally ages 15 and 16), teleiophilia (adults in Tanner Stage 5, between the ages of physical maturity and physical decline), and gerontophilia (the elderly).

One of these preferences (teleiophilia) and possibly a second (ephebophilia) are generally considered normophilic. Two of them (gerontophilia and pedophilia) are generally considered paraphilic. The remaining preference (hebephilia) is classified differently in major diagnostic systems. This difference in the classification of hebephilia may not be immediately apparent, because the major diagnostic systems also use diagnostic labels differently.

Two major medical organizations publish corporately authored diagnostic manuals that include definitions of pedophilia: the American Psychiatric Association, which publishes the DSM (Diagnostic and Statistical Manual of Mental Disorders), and the World Health Organization, which publishes the ICD (International Statistical Classification of Diseases and Related Health Problems). Their definitions of pedophilia are somewhat different. The DSMIV-TR definition is embedded in its diagnostic Criterion A: "Over a period of at least 6 months, recurrent, intense sexually arousing fantasies, sexual urges, or behaviors involving sexual activity with a prepubescent child or children (generally age 13 years or younger)" (American Psychiatric Association, 2000, p. 572). The ICD-10 definition of pedophilia is "A sexual preference for children, boys or girls or both, usually of prepubertal or early pubertal age" (World Health Organization, 1992, p. 171).

It can therefore be seen that the main difference between the ICD-10 and DSM-IV-TR definitions is the inclusion of hebephilia under the heading of pedophilia. The second author of this letter (R.B.), a member of the Paraphilias Subworkgroup of the Work Group on Sexual and Gender Identity Disorders for DSM-5, proposed a diagnostic entity for DSM-5 that resembles the ICD-10 model, but with a different name: Pedohebephilic Disorder. In the original proposal (Blanchard, 2010a), this disorder would have three subtypes: pedophilic, hebephilic, and pedohebephilic. In the current version of the proposal, which is still under consideration, the name has been changed to Pedophilic Disorder, in order to harmonize the label as well as the content with its ICD-10 counterpart, and the subtypes have been changed to classic, hebephilic, and pedohebephilic.

Franklin (2009) objected to the proposal to roll hebephilia into the diagnosis of Pedophilic Disorder in DSM-5 on the grounds that "such attractions are evolutionarily adaptive" (p. 319). She did not explain this argument any further. Presumably, she meant something along the following lines: In the environment of evolutionary adaptedness, men with a sexual preference for early pubescent females had greater reproductive success, either because they acquired female mates near the onset of their fecundity and thus prevented them from being impregnated by other men, or because they had more years in which to impregnate their mates themselves, or both. According to Franklin, since hebephilia is of evolutionary design, it cannot be a mental disorder. Franklin's hypothesis was probably intended to explain hebephilia only in heterosexual men, since pubescent boys cannot become 
pregnant any more readily than prepubescent boys. In any event, she did not address why homosexual pedophilia might be considered a disorder but homosexual hebephilia should not.

Franklin's hypothesis was tested by Blanchard (2010b), who compared the mean numbers of biological children reported by 818 heterosexual teleiophiles, 622 heterosexual hebephiles, and 129 heterosexual pedophiles. The results showed that the teleiophiles had significantly more children than the hebephiles, and the hebephiles had significantly more children than the pedophiles. Blanchard (2010b), who had pointed out that there is nothing in the contemporary environment that would completely abolish the relation between hebephilia and fertility postulated by Franklin for the ancestral environment, concluded that there was no empirical basis for the hypothesis that hebephilia was associated with increased reproductive success in the environment of evolutionary adaptedness.

Franklin (2010) criticized Blanchard's (2010b) empirical test of her hypothesis. She included, among her objections, the assertion that "Plunging birth rates in developed nations alone create a low ceiling effect for this outcome variable" (p. 819). The relevance of this objection is unclear. It is obvious that a ceiling effect might explain a failure to find that hebephilic men have significantly more offspring than teleiophilic men, but it cannot explain why hebephilic men actually have significantly fewer offspring than teleiophilic men.

Franklin's notion about the "evolutionary adaptiveness" of hebephilia continues to be echoed by other authors (see Blanchard, 2012). The present writers therefore undertook to consider this notion further. The problem we face in examining the empirical and logical bases of potential evolutionary rationales for the adaptiveness of hebephilia is that they are not adequately elaborated or documented. We note some of the specific limitations as we evaluate the evidence below.

In her original article, Franklin (2009) cited Kenrick and Keefe (1992) to support her hypothesis that hebephilia (which she treats as synonymous with any detectable degree of sexual attraction to pubescent girls) is "evolutionarily adaptive" (p. 319). Kenrick and Keefe's survey, however, says nothing about the attractiveness of girls to men. The focus is on attraction to women of various ages, and the facts that men prefer women a few years younger than they are and women prefer men who are a few years older. An interesting finding in that survey is that, as men age, the age of the women they prefer also increases, thus directly contradicting Franklin's thesis. Kenrick and Keefe then go on to develop an evolutionary rationale for why men should shift their age preferences through time. Thus, Kenrick and Keefe's survey provides strong evidence against Franklin's adaptationist hypothesis of hebephilia.

In a Psychiatric Times blog post entry, Frances (2011) claims that

The basic issue is that sexual attraction to pubes- cent youngsters is not the slightest bit abnormal or unusual. Until recently, the age of consent was age 13 years in most parts of the world (including the United States) and it remains 14 in many places. Evolution has programmed humans to lust for pubescent youngsters-our ancestors did not get to live long enough to have the luxury of delaying reproduction. ... It is natural and no sign of mental illness to feel sexual attraction to pubescent youngsters.

Although it is true, as Frances notes, that pubescent girls can be married or betrothed in some societies, this does not mean sex occurred at marriage or betrothal or that such girls were regarded as more sexually desirable than physically mature women. There is very little crosscultural data on the topic of whether married pubescent girls had sex with their husbands. The best information we have is from Whiting's (2009) work on maidenhood. Whiting defined maidenhood as the interval between menarche and marriage. After examining the Human Relations Area Files (a data base of world cultures studied by ethnographers), Whiting found 58 societies with adequate information on maidenhood (Table 33, p. 385). Of those 58 , he classified only $9(15.5 \%)$ as "restricted or absent" for maidenhood, which means they permitted husbands to have sexual intercourse with their brides at or just before menarche. In societies permitting marriage or betrothal of pubescent girls, such marriages are designed to ensure female virginity, and, in the majority of these societies, premarital and extramarital sex are strongly prohibited. It is therefore safe to say that sex with pubescent girls is uncommon cross-culturally.

Frances' second claim that our ancestors did not live long enough to delay reproduction is contradicted by what we know of the demography of hunter-gatherers and simple horticulturalists, which are the best models of what human life-spans were like during what is commonly known as the environment of evolutionary adaptedness. Perhaps Frances' confusion about human life-spans stems from dated and poor research from bioarchaeological remains or misleading use of life expectancy at birth $\left(\mathrm{E}_{0}\right)$ estimates, which typically ranges from 21 to 37 years in simple societies (Kaplan \& Gurven, 2007). The latter distorts longevity because of very high infant mortality rates. In a comprehensive review of the highest quality demographic data on simple human societies, Kaplan and Gurven $(2007$, p. 334) showed that the modal age at death (assuming one survives to age 15) is about 72 years (range, 68-78), whereas the modal age at death in the United States (2002) is 85 years. Clearly, longevity has increased in the modern era, but hunter-gatherer data show that we are a naturally long-lived species. More to the point, those who survived to the age of 15 had many decades of life to seek mates.

Aside from the above-mentioned empirical problems with evolutionary models of sexual preference for pubescent girls, there are numerous logical pitfalls. In a survey of 22 hunter-gatherers and simple horticulturalists, 
Walker et al. (2006, p. 300, Table 2) found age at menarche to be about 15 and age at first reproduction to be about 19. Following Franklin, if one were preferentially attracted to pubescent girls in order to prevent them from being impregnated by other men, then one would have to wait an average of four years before realizing any reproduction. During that interval, three events could occur to make that tactic a poor strategy: The husband could die, the wife could die, or they could divorce.

Finally, Kramer's (2008) work on the hunting and gathering savanna Pumé of Venezuela echoes Blanchard's findings on reproductive success and attraction. Kramer compared the number of surviving children born to women who began their reproductive careers early ( $<14$ years), mid (14-16 years), and late ( $\geq 17$ years). Over their lifetimes, women who bore children early had fewer numbers of surviving children than mid- or late-bearers. The major factor accounting for these differences was the very high rates of infant mortality for early bearing women. As in Blanchard's study, what this means is that men who had a preference for the youngest females would have the lowest reproductive success.

We believe the data we have presented here clearly demonstrate that not only is hebephilia not an adaptation but more reasonably a maladaptation in both ancient and modern environments.

\section{References}

American Psychiatric Association. (2000). Diagnostic and statistical manual of mental disorders (4th ed., text rev.). Washington, DC: APA.

Blanchard, R. (2010a). The DSM diagnostic criteria for Pedophilia. Archives of Sexual Behavior, 39, 304-316.
Blanchard, R. (2010b). The fertility of hebephiles and the adaptationist argument against including hebephilia in DSM-5 [Letter to the Editor]. Archives of Sexual Behavior, 39, 817-818.

Blanchard, R. (2012). [Letter to the Editor]. Journal of the American Academy of Psychiatry and the Law, 40, 157-158.

Blanchard, R., Kuban, M. E., Blak, T., Klassen, P. E., Dickey, R., \& Cantor, J. M. (2012). Sexual attraction to others: A comparison of two models of alloerotic responding in men. Archives of Sexual Behavior, 41, 13-29.

Frances, A. (2011, December 15). Hebephilia is a crime, not a mental disorder. Online @ http://www.psychiatrictimes. com/blog/frances/content/article/10168/2006997.

Franklin, K. (2009). The public policy implications of "hebephilia": A response to Blanchard et al. (2008) [Letter to the Editor]. Archives of Sexual Behavior, 38, 319-320.

Franklin, K. (2010). Why the rush to create dubious new sexual disorders? [Letter to the Editor]. Archives of Sexual Behavior, 39, 819-820.

Kaplan, H., \& Gurven, M. (2007). Longevity among huntergatherers: A cross-cultural examination. Population Development Review, 33, 321-365.

Kramer, K. (2008). Early sexual maturity among Pumé foragers of Venezuela: Fitness implications of teen motherhood. American Journal of Physical Anthropology, 136, 338-350.

Walker, R., Gurven, M., Hill, K., Migliano, A., Chagnon, N. A., Hames, R., et al. (2006). Growth rates and life histories in twenty-two small-scale societies. American Journal of $\mathrm{Hu}$ man Biology, 18, 295-311.

Whiting, J. (2009). The duration of maidenhood across cultures, in E. H. Chasdi (ed.), Culture and human development: The selected papers of John Whiting (pp. 282-305). Cambridge: Cambridge University Press.

World Health Organization. (1992). International statistical classification of diseases and related health problems (10th rev., Vol. 1). Geneva, Switzerland: WHO. 